\title{
Areas of Improvement of Organization and Research of Educational Management Problems
}

\author{
Tetiana V. Sych \\ Luhansk Taras Shevchenko National University \\ Andrii O. Diegtiar \\ National Aerospace University "Kharkiv Aviation Institute" \\ Tamara M. Lozynska \\ Kherson National Technical University \\ Ivan P. Lopushynskyi \\ Kherson National Technical University \\ Svitlana M. Vovk \\ Donetsk National Medical University
}

The relevance of the paper was determined by the fact that modern domestic system of young scientists' training is in the process of reforming. The purpose of the article is to outline the directions of improving the training of scientists and organization and conduct domestic research in the field of education management on the basis of comparison of world and domestic research experience. The areas of improvement of scientists' training, organization and carrying out domestic scientific research of problems of management of education are defined on the basis of the received results, taking into account world tendencies. The authors make conclusions about the need to increase the methodological literacy of domestic scientists and direct their training to master various models and forms of research, modern qualitative and quantitative research methods, methods using software used for scientometric and semantic analysis of scientific literature, methods of mathematical statistics.

Keywords: research methodology, world experience, education management, training of scientists

\section{INTRODUCTION}

Economic development, quality of social life is directly dependent on the state of science and education development. The process of efficiency of scientific activity is influenced by many factors: from the training of young scientists to the mechanisms of organization, research, and implementation of their results. The modern domestic system of young scientists' training is in the process of reforming. Bringing it in line with world standards of higher education, training doctors of philosophy (Ph.D.), improving the content and 
procedural components require the study of global trends, experience in organizing and conducting research, comparing them with domestic requirements for scientific research, and representation of research results. scientific degrees and conferring academic titles in Ukraine, etc.

The analysis of scientific literature on this problem showed that in domestic science a significant amount of thorough research is devoted to the educational systems of a particular country. An example of such research within the specialty 13.00.01 "General pedagogy and history of pedagogy" is the research of A. Maksymenko (2008), which outlines the formation and development of the university education system in France (XIX- XX centuries), O. Bocharova (2006) considered the problem of modernization of higher education in modern France is, etc. Within the specialty 13.00.06 "Theory and methods of education management" in O. Kalinina's (2015) research the system of education quality management in higher educational institutions of the USA is described, in S. Burdina's (2008) work the system of training of masters of education management in higher educational institutions of the USA is covered.

Several works in these specialties are devoted to the comparison of higher education in several countries, namely: A. Rzhevska (2013), who examines the development of modern university education in Western Europe, V. Vakulenko (2008), who considers a comparative analysis of the use of acmeological approach in higher pedagogical education of Ukraine, Belarus; O. Slyusarenko (2015) examines the development of the highest university potential in the context of globalization: analysis of world experience; G. Poberezska (2005) analyzes trends in higher education in Western Europe and Ukraine and others.

There are not many works devoted directly to the analysis of the experience of world research practice and its comparison with the domestic one. Among such works, there is the publication of S. Ivakhnenkov and J. Conber (2015), which presents the results of research on the requirements for study in writing a dissertation of a candidate of science in Ukraine and a dissertation of a doctor of philosophy (Ph.D.) in management and finance in the United States. Comparison of the world and domestic requirements for the structure of dissertations, presentation of scientific results, formation of research issues is carried out in the study of T. Sych (2020), devoted to the development of methodology of researching education management in the history of domestic pedagogy (second half of XX - early XXI century).

\section{MATERIALS AND METHODS}

During the study, more than 400 abstracts of dissertations of pedagogical specialties devoted to the problems of education management and protected in Ukraine in the period from the 1950s to 2018 were analyzed. 97 abstracts of dissertations of the specialty 13.00.06 "Theory and methods of education management" are thoroughly considered, which is $67 \%$ of works protected under the code of this specialty in 2008-2018. Based on the systematization and generalization of empirical data, conclusions on the structure of works, methodological principles, and systems of research methods for education management problems are made (Wang, 2021). Based on the results of the analysis of the official websites of the Ministry of Education and Science of Ukraine, the Academy of Pedagogical Sciences of Ukraine, the study of scientific literature and abstracts of dissertations, conclusions on the formation of research topics were drawn. Comparative analysis was used to compare world and domestic experience in organizing and conducting research. Methods of generalization and forecasting - to determine areas for improving the organization and research of education management problems in the domestic pedagogical science.

There is a significant difference in the system of training scientists. In the author's opinion for a long time the Ukrainian system of postgraduate training was aimed at considering philosophical methodological provisions, general scientific methods, provided for mastering courses mainly in preparation for the candidate exams, and was more focused on the self-education of scientists. To the author's mind, insufficient attention was paid to the technological component of the research methodology and consideration of its specifics in relation to the features of the specialty. This is confirmed by the analysis of more than 50 domestic educational and methodological publications on the methodology of scientific research (Lu et al., 2021), which are mostly devoted to the disclosure of the philosophical foundations of cognitive activity; defining the principles, levels, functions, objectives of research methodology, the importance of ethical principles and culture of the researcher; disclosure of the creative essence of scientific 
research, the essence of the scientific apparatus; outlining the general principles of organization of scientific research, testing, and implementation of the results, requirements for registration, defense of dissertations, etc. Much attention is usually paid to the consideration of general scientific logical methods and techniques of cognition, as well as empirical research methods. Methods of mathematical statistics are not considered in every textbook and mostly in general (Sych, 2020).

The system of grant research implementation has been introduced in Ukraine in recent years. The implementation of grant projects allows to solve the issue of their funding and ensures the relevance of the problem of research, allows engaging in comparative international research. It should not be forgotten that the relevance of research topics, in this case, is determined by those who finance grants (Selezneva, 2020). Therefore, for the development of the domestic education system, it is important to have domestic institutions that would provide grant support and determine the main directions of domestic research, including the problems of education management.

\section{RESULTS AND DISCUSSION}

The analysis of domestic dissertations on the problems of education management showed that in the 1950s and 1960s there was a subjective view on forming the topics. The choice of topic was determined by the personal interests of scholars, who were usually managers-practitioners and described the experience of their leadership. In the 1970s, the main source of information on the relevance of educational problems in domestic science was educational practice. In those years, planning and forecasting of pedagogical research, determining the criteria of their effectiveness, implementation of research results in practice were developed by the laboratory of forecasting and planning problems and the laboratory of planning methods of pedagogical research of the Research Institute of General Pedagogy of the USSR in cooperation with the complex science problem department of Ukrainian Academy of Sciences. Data on the real needs of practice on the relevance of research topics were obtained through surveys of management and teaching staff of educational institutions and departments of public education; analysis of correspondence of schools with public education departments, materials of inspections, minutes of public education councils meetings, topics of periodicals, etc. (Khrykov, 2017). Thus, an empirical means of forming scientific issues was used in combination with the party's directives and attitudes.

In the 1980s, the communist regime weakened and the mechanism for determining the problems of research by a subjective means, combined with the directive method, which was traditional for modern domestic science in the pedagogical field, was formed. Since 1992, the Higher Attestation Commission of Ukraine (HAC of Ukraine) has been responsible for determining the requirements for the design of dissertations and the procedure for awarding scientific degrees and awarding academic titles of Ukraine. Since 2010, these functions have been performed by the Certification Board of the Ministry of Education and Science of Ukraine. Since 1995, the Interdepartmental Council for Coordination of Research in the Field of Education, Pedagogy, and Psychology has been established based on the Academy of Pedagogical Sciences of Ukraine. The main directions of the work of the Council are coordination of dissertation topics, their publication on the website of the National Academy of Pedagogical Sciences of Ukraine, identification of priority areas of research, and publication of annual reports on scientific activities in the field of pedagogy and psychology in Ukraine (Interdepartmental Council... 2019).

In the world of modern reforms of higher education, domestic higher educational institutions have gained autonomy, are more independent in the choice of topics. However, the mechanism for choosing research topics remains the same. The initiator of the study is a scientist, who is usually an employee of a higher educational institution and conducts scientific research to obtain a scientific degree. He chooses the topic by his interests, coordinates it at the level of a higher educational institution and the state, and becomes the main sponsor for financing its implementation. In world practice, research activities are carried out quite often within the framework of grant projects, which allows to solve the issue of their funding and ensures the relevance of research issues. Also, common practice is the world practice of organizing and conducting comprehensive research, which is carried out by teams of authors within the projects of research centers at universities, civic organizations (e.g, American Association for Educational Research (AERA)), 
international associations (e.g, International Association for Academic Assessment) (IEA)) and others (Bkhattacherdzhy and Sytnyk, 2016).

The content of the textbook of the University of South Florida in the USA (Bkhattacherdzhy and Sytnyk, 2016) testifies to its practical orientation. Its purpose is to help a novice researcher to choose a research strategy within a certain scientific paradigm and provide practical guidance on its implementation. The basics of scientific knowledge are considered through the representation of modern scientific paradigms, namely: radical structuralism, radical functionalism, radical humanism, and interpretive paradigm. The theory of scientific knowledge is considered in accordance with scientific approaches to its construction and combination with practical advice. This is complemented by a brief overview of some illustrative theories from various social disciplines and the delineation of the criteria for "good theories".

The technology of organization of scientific research is carefully considered, the characteristic of its stages is given and the requirements to carrying out are outlined. A description of the key elements of the design quality of the study (complex data collection plan), namely: internal validity, external validity, the validity of constructs, and validity of the statistical conclusion. Selection conditions and various examples of research design (experimental, production survey, case study, secondary data analysis, focus group research, action research, ethnography) are given. The methods of data collection are thoroughly described, which are grouped into two categories: positivist (deductive: an experiment and questionnaires aimed at testing theories (hypotheses)) and interpretive methods (based on the inductive approach and try to build a theory of the studied objects based on the obtained empirical data). Also, considerable attention is paid to examples of the application of descriptive and explanatory statistics, questions of ethics of scientific research.

S. Ivakhnenkov concludes that US scientists are generally fluent in the methods of mathematical statistics and must use them in research in various scientific fields. His conclusions are based on the analysis of scientific articles in specialized journals (Ivakhnenkov and Conber, 2015). However, according to the results of our analysis of abstracts of domestic studies of management problems defended in 2008-2018, the methods of mathematical statistics were used only in $57 \%$ of studies (Sych, 2020). Therefore, it is important for the domestic system of scientific training to implement new programs and plans for their training in accordance with world standards of education. In recent years postgraduate study involves mastering the educational program in 30 credits, which should increase their methodological level. However, this is realized under the condition of adjusting the content of education, directing it to the practice of research in accordance with the specifics of the subject of specialty and specific research.

There are significant differences in the world and domestic methodology of organizing and conducting research in the training of scientists in post-graduate school. In domestic practice, it is common for a scientist to coordinate a topic with a higher educational institution first, and even approve it, and then enter post-graduate school (Biricheva and Fattakhova, 2021). At the stage of coordination of the the research topic, the scientists substantiate the relevance of the topic, determine the object, subject, purpose, and objectives of the research. There are no requirements for the formulation of the hypothesis. Indeed, in the course of the research, partial changes may be made to the formulation of the topic and the scientific apparatus of the research may be adjusted. In world practice, the topic of research is defined in the "doctoral proposal" after one year of study in the "doctoral program" (Ph.D. studies). At the stage of defining research topic, considerable attention is paid to the formulation of the research hypothesis ("research proposal"), the object, subject, purpose of the research are not defined at all (Ivakhnenkov and Conber, 2015).

S. Ivakhnenkov and J. Conber (2015) compare the requirements for research in writing a dissertation for a Ph.D. in Ukraine and the requirements for dissertations (Ph.D.), which are based on positivist epistemology and are carried out in countries such as the United States, Great Britain, Canada, Australia, Ireland. The results of their analysis and the results of our study of the application and implementation of methodological principles in domestic studies of education management allow us to conclude that there is a fundamental difference not only at the level of research methodology but also at the level of work structure, conceptual understanding of methodology, drawing conclusions, etc. In foreign studies, the methodology is defined as a type of research strategy (experiments, correlation studies, causal studies, positivist cases, meta-analysis) and a description of methods for obtaining and processing results. Research 
is aimed at confirming or refuting the theory, paying considerable attention to the definition of procedures, planning details, the order of research, systematic collection, analysis, and comparison of empirical data.

In Ukrainian works, the methodology is more often revealed with the help of methodological principles (philosophical positions and principles, provisions of separate theories, philosophical, general scientific, and concrete-scientific approaches); theoretical principles (general provisions of pedagogy and other sciences, provisions of specific theories, documents, scientific works); methods (theoretical, empirical and methods of mathematical statistics). Accordingly, Ukrainian scientists tend to define basic scientific and philosophical categories, specify the scientific apparatus of research, clarify the meaning of scientific terms, trace historical development, define functions, implement classifications, and more.

In the author's opinion, the emergence of such differences is due to the peculiarities of the development of domestic research methodology, which has been formed within the framework of philosophical knowledge and under the influence of the ideas of Marxist-Leninist dialectics for a long time. Therefore, Ukrainian scientists tend to excessive theoretical, philosophical, historical, and genetic analysis of scientific problems and group methodology based on dialectical materialism. This is confirmed by the results of our analysis of Ukrainian studies in the specialty 13.00.06, defended in 2008-2018, in most of which scholars indicate the application of dialectical principles and provisions at the philosophical level of methodology (Ivakhnenkov and Conber, 2015).

Modern American scholars usually base their research on a different philosophical ground - positivism, and interpretivism. Significant differences can be traced in the structure of dissertations. In the world practice in positivist researches the following structure of work from five parts is widespread:

1. a problem, a purpose, a research question/hypothesis;

2. literature review;

3. methodology;

4. conclusions; discussion (Ivakhnenkov and Conber, 2015).

The structure of domestic research in the latest version of the requirements of the HAC of Ukraine provides such parts: introduction (prove the relevance of the study, determine the purpose and objectives, object and subject, methods, connection with scientific programs, plans, topics, grants, scientific novelty and practical significance of research results, provide their approbation, publications of the applicant, structure and volume of dissertations); main part, conclusions, list of sources, appendices (if necessary); annotation (Order of the Ministry of Education and Science of Ukraine No. 40... 2017). Thus, according to the requirements of the delineation of the research methodology, the introduction presents only the definition of methods, and the delineation of methodological and theoretical principles, which is carried out at the initiative of scientists.

Interestingly, the main section of the dissertation according to the Reference Book of 2000 should contain "a review of the literature on the topic and choice of research areas; presentation of general methods and basic research methods; experimental part and research methodology; information about conducted theoretical and (or) experimental researches; analysis and generalization of research results" (Tsekov, 2000). Thus, there is a section devoted to the disclosure of research methodology, which coincides with the structure of research in world practice. However, the need for such a section is refuted in the wording of the requirements of 2017, in paragraph 9 of these requirements, the content of the sections is outlined in a fairly general form: "In the sections of the dissertation it should be fully set out the content of the own research of the degree applicant, reference is made to all scientific works of the applicant, given in the annotation..." (Order of the Ministry of Education and Science of Ukraine No. 40... 2017).

Accordingly, in the practice of research on the problems of education management, the paragraph with the disclosure of research methodology can be found only in doctoral dissertations. The structure of the main part of two sections is widespread in the candidate's works:

1) theoretical/theoretical-methodological principles of management processes or other phenomena under study;

2) to substantiate the control model and the description of the experiment.

The description of the research methodology is branched out throughout the work, the paragraph on the research methodology is usually absent, which does not correspond to the world research practice and does 
not contribute to improving the quality of scientific research. Instead, considerable attention is paid to the retrospective review of the literature in the first theoretical section, as well as in the second section, even when describing the experiment and the results of its implementation. In world practice, the literature review is carried out in the second part and should consist of coverage of the results of discussions of the research problem, mainly in publications of the last 5 years. Instead, much attention is paid to the description of research strategy and the use of methods of mathematical statistics.

Significant differences were found at the level of presentation of work results and formation of conclusions. In domestic practice, in practice-oriented research on the problems of education management, the result is the author's management model, the effectiveness of which is tested experimentally, and suggestions for the implementation of this model should be given. The section where the result is specifically presented is the conclusion, in which the results of the research are usually presented in 3-9 points in accordance with the set tasks.

Testing of the results is confirmed by the mandatory implementation. This mandatory requirement has been established since 1992 based on the "Regulations on the Procedure for Awarding Scientific Degrees and Awarding Academic Titles of Ukraine". According to the current version of this document from 2019, this requirement has not changed: "The dissertation containing scientific and applied results must be accompanied by documents confirming the practical use of the results obtained by the applicant introduction into production, sufficient research and production testing, obtaining new quantitative and qualitative indicators, significant advantages of the proposed technologies, product samples, materials, etc., and to the dissertation, which contains theoretical scientific results - recommendations for their use" (Order of the Ministry of Education and Science of Ukraine No. 40... 2017).

Confirmation of the importance of the results of work and compliance with these requirements requires scientists to conduct large-scale research on the basis of 5-6 to 12 or more educational institutions. However, given that these studies are individual and conducted mainly at the expense of the researchers themselves, the question arises as to the quality of their implementation, especially at the level of relatively short research for the degree of candidate of sciences, and the consequences and effectiveness of these numerous implemented results which have been implemented over all these years in the domestic education sector.

In world research practice, the conclusions are understood as "a certain new knowledge (which proves or refutes the hypothesis), often a single observation or thesis" (Ivakhnenkov and Conber, 2015), while the problems of implementation are not considered in the conclusions, proposals for the implementation of the results are not mandatory, but the possible consequences for further research should be indicated. In world practice, the study of specific situations is quite common (case studies that describe, analyze systems, historical processes, any innovation, a special national situation in education, etc.). Indicative in this regard, for example, is a data of the World Congresses of Comparative Education Organizations, according to which in 1984-1985 case studies accounted for 45\% of all studies in Rio de Janeiro (Bray et al., 2015).

The strength of this method lies in its ability to identify a wide range of social, cultural, and political factors that are potentially related to the phenomenon under study. The results of one case may not be sufficient for generalization in other situations, but the level of generalization of conclusions based on case studies may increase by repeating the research and comparing the results of analysis of other cases in multicase designs. This type of research can be effective and efficient in the implementation of research activities in the field of education management, aimed at studying open probabilistic educational systems, which are characterized by the uncertainty of results and the presence of self-organization processes. Its introduction into domestic research practice requires a revision of domestic requirements for mandatory experimental substantiation and testing of research results by numerous proceedings.

\section{CONCLUSIONS}

Comparison of domestic and world practice in training young scientists, organization, and conduct of research revealed a number of significant differences in the direction of training $\mathrm{PhDs}$, mechanisms for determining research topics and their funding, forms and models of research, dissertation structure, understanding the methodology and justification of research, requirements for proof of results and 
formation of conclusions, etc. The obtained results indicate the need to increase the methodological literacy of domestic scientists and direct their training to master various models and forms of research, modern qualitative and quantitative research methods, methods using software, which used to perform a scientometric and content analysis of scientific literature, methods of mathematical statistics, etc.

It is necessary to improve the requirements for the structure of dissertations on the mandatory disclosure of research methodology in a separate section, which substantiates the methodological principles, research strategy and methods and techniques; as well as proof of research results in accordance with world research practice. To ensure the advanced development of scientific knowledge, it is important to improve the mechanisms of formation of research issues of pedagogical research, in particular the problems of education management. Namely, the introduction of mechanisms for collecting information from educational institutions on current issues that need a scientific solution based on modern information technology to obtain such information, generalize this information at the level of Ukraine, and provide access to it for scientists by creating a database on research needs. Such a bank can also summarize information on world research, grants, projects, and conditions for the participation of domestic scientists.

Global trends in conducting complex collective interdisciplinary and comparative research require the dissemination of this experience in domestic science, improving the mechanisms for involving Ukrainian scientists in international projects. As well as maintaining the practice of collective research in the domestic scientific community and the formation of the domestic grant system of research, which will provide adequate funding for research and implementation of research results in educational practice.

\section{REFERENCES}

Biricheva, E.V., \& Fattakhova, Z.A. (2021). The effectiveness of interaction between scientific supervisors and graduate students at the university and at the academy of sciences. Vysshee Obrazovanie v Rossii, 30(1), 9-22.

Bkhattacherdzhy, A., \& Sytnyk, N.I. (2016). Methodology and organization of scientific research: Research in the socio-economic sciences (p.159). Kyiv: National Technical University of Ukraine "Igor Sikorsky Kyiv Polytechnic Institute".

Bocharova, O.A. (2006). Modernization of higher education in modern France (p.20). Kyiv: Institute of Higher Education of the Academy of Pedagogical Sciences of Ukraine.

Bray, M., Adamson, B., \& Meison, M. (Eds.). (2015). Research on Comparative Education: Approaches and Methods (p.380). Luhansk: FOP "Sabov A.M.” Publishing House.

Burdina, S.V. (2008). The system of training masters of education management in higher education institutions of the United States (p.20). Luhansk: Luhansk Taras Shevchenko National University.

Interdepartmental Council for the Coordination of research in the field of education, pedagogy and psychology. (2019). Retrieved from http://naps.gov.ua/ua/iccr/

Ivakhnenkov, S.V., \& Conber, D. (2015). Approaches of US scientists to the methodology of science: A study plan for reforming business research in Ukraine. Proceedings of NaUKMA, Economic Sciences, 172, 33-38.

Kalinina, O.H. (2015). The quality management system of education in higher education institutions in the United States (p.21). Luhansk: Luhansk Taras Shevchenko National University.

Khrykov, Y.M. (2017). Methodology of pedagogical research (p.237). Kharkiv: FOP "Panov A.M." Publishing House.

Lu, K., Yang, H.H., Shi, Y., \& Wang, X. (2021). Examining the key influencing factors on college students' higher-order thinking skills in the smart classroom environment. International Journal of Educational Technology in Higher Education, 18, article number 1.

Maksymenko, A.P. (2008). Formation and development of the French university education system (XIX$X X$ centuries) (p.36). Kyiv: Institute of Higher Education of the Academy of Pedagogical Sciences of Ukraine. 
Order of the Ministry of Education and Science of Ukraine No. 40 "On approval of the Requirements for the formation of the dissertation". (2017, January). Retrieved from https://zakon.rada.gov.ua/laws/show/z0155-17.pdf\#Text

Poberezska, H.H. (2005). Trends in the development of higher education in Western Europe and Ukraine (p.22). Kyiv: Institute of Higher Education of the Academy of Pedagogical Sciences of Ukraine.

Rzhevska, A.V. (2013). Development of modern university education in Western Europe (p.400). Luhansk: Luhansk Taras Shevchenko National University.

Selezneva, Y. (2020). Innovative potential of a teacher in a new reality: Challenge and response. E3S Web of Conferences, 210, article number 18041.

Sliusarenko, O.M. (2015). Development of modern university education in Western Europe development of the highest University potential in the context of globalization: An analysis of world experience (p.435). Kyiv: Institute of Higher Education of the Academy of Pedagogical Sciences of Ukraine.

Sych, T.V. (2020). Development of research methodology of education management problems in history of domestic pedagogical science (the second half of the 20th-The beginning of the 21st century (p.761). Kharkiv: Ivanchenko I.S. Publishing House.

Tsekov, Y.I. (Ed.). (2000). Reference book of the academic degree applicant (p.64). Kyiv: "Biul. VAK Ukrainy".

Vakulenko, V.M. (2008). Acmeological approach in the theory and practice of higher pedagogical education in Ukraine, Belarus, and Russia (comparative analysis) (p.44). Luhansk: Luhansk Taras Shevchenko National University.

Wang, Y. (2021). Educational management system of colleges and universities based on embedded system and artificial intelligence. Microprocessors and Microsystems, 82, article number 103884. 